\title{
Analysis on the Advantage of High Quality Employment of Graduates from Private Colleges and Universities
}

\author{
Juan Du \\ International Cooperation \& Exchange Office, Xi'an Traffic Engineering Institute, Xi'an 710300, \\ China \\ 2391646434@qq.com
}

\begin{abstract}
This paper analyses the employment advantages of private university students from five aspects, and suggests that by discovering, tapping and strengthening their own advantages, the employment quality of private university students can be effectively improved, which is of great significance to the implementation of the central government's guiding spirit of "promoting the realization of higher quality employment".
\end{abstract}

Keywords: Private college and Universities; High Quality Employment; Advantages.

\section{Introduction}

In the 2012 report of the 18th National Congress of the Communist Party of China, it emphasized "to promote the realization of higher quality employment", which has attracted wide attention from all sectors of society. Some surveys show that there are different understandings of high-quality employment by university students, such as higher salary, reasonable social security, and good personal development prospects. However, the interpretation of high-quality employment among the university students is not completely the same. The employment quality of graduates of key universities such as " 985 " and " 211 " is very stable, and basically, they can achieve high-quality employment. More than $90 \%$ of China's TOP100 listed companies take the initiative to recruit in these universities. However, it is difficult for ordinary universities, especially private ones, to achieve high-quality employment. What are the employment advantages of private university students? and How to effectively improve their the employment quality through discovering, tapping and strengthening their own advantages is significant to the implementation of the central government's guiding spirit of "promoting the realization of higher quality employment".

In the academic literature on the employment quality of university students, the research is mainly concluded from three aspects: the research on employment quality; research on the factors affecting the employment quality of university students; and research on the employment advantage of private university students.

\section{Content of Employment Quality}

With regard to the quality of employment, the International Labour Organization (ILO) has compiled a set of 14 indicators to measure decent work, including adequate income, job stability, social security and so on. The recommended indicators for the evaluation of job quality by the European Commission (2001) including 10 dimensions: internal work quality, skills, lifelong learning and career development, gender equality, health and work safety, etc.

The study of Chinese scholars generally regards wage income as the core factor and emphasizes labor relations and social security. Schroeder (2007) argues that high-quality employment refers to the ability of individuals to earn the income they need to make a living in a comprehensive environment in which they can find jobs that are both challenging and satisfying. The author believes that it is not universal to evaluate the quality of employment with the indicators of salary level, whereas different regions, industries and groups have different expected salary levels, therefore, it is representative and applicable to express job satisfaction as the quality of employment. 


\section{The Factors Affecting the Employment Quality of University Students}

There are many research results on the factors affecting the quality of employment, but the conclusions are different and there are few studies on the characteristics of students in private universities. The research of Liu and $\mathrm{Hu}$ (2008) shows that the university graduates' gender, age, political status, place of origin, household registration and type of major have a significant impact on their employment status. Huang (2007) believed that personal effort, comprehensive quality, employment intention and employment behavior would affect employment ability. Wei and $\mathrm{Fu}(2006)$ proposed that the national policy, employment attitude, self-quality and school-running characteristics are the main factors affecting the employment quality of private university graduates. Jiang (2015) conducted a study in a private university in Anhui Province, and proposed that school education and teaching, student employment attitude, school employment guidance and employment funding are some factors that affect the quality of employment.

Tang et al. (2015) based on the perspectives of schools and individuals, from the macro and micro level, analyzed the factors influencing employment quality of graduates from private universities. At the macro level, the paper analyzes how the majors and the school impact the employment of university students from the overall employment trends of the school; the micro level is the impact of individual employment ability and personal natural information on university students' employment. Jiang and Song (2010) believe that the major setting of private universities in China generally follows the market closely, and the curriculum setting is practical and scientific, whereby the students cultivated by them have advantages that the public university students do not have.

The author believes that whether private university students can give full play to their unique advantages is an important factor affecting their employment quality. Moreover, the initiative to exert its own advantages is largely in the hands of the school and the students themselves.

\section{Employment Advantage of Private University Students}

$\mathrm{Li}$ (2015) believes that the employment status of private university graduates is relatively inferior to that of public universities. Private colleges and universities should give full play to their advantages of flexible school-running mechanism, greater autonomy in running schools, and the initiative and driving force of strong development. Shen and Wang (2015) proposed that private colleges and universities should focus on cultivating application-oriented talents, and the improvement of their graduates' employment competitiveness should begin with habit formation, and start from students' internal causes to enhance three basic non-intellectual factors: work motivation, personal characteristics and work style.

The author believes that the employment advantages of private university students can be summarized as five advantages: market proximity, professional skills, multiple intelligence, low expectations and risk tolerance advantages. Analysis what employment advantages already existed, which employment advantages have been exerted, and which advantages still need to be explored. Finally, according to the results of empirical analysis, propose targeted policy recommendations.

\subsection{The Major is Close to the Market Demand.}

Private colleges and universities are basically employment-oriented, the major setting and adjustment, curriculum setting and adjustment all closely following the market demand. Under normal circumstances, private colleges and universities generally do not set up unpopular majors like philosophy and history. However, if everyone is rushing to catch up with the hotspots, they may oversupply and lose their characteristics, which is counterproductive. Therefore, to achieve highquality employment through major setting, it is necessary to study whether it is in short supply in the market, and whether the curriculums were useful.

\subsection{Mastery of Professional Skills.}

A considerable number of private colleges and universities are oriented towards cultivating applied and skilled talents; pay much more attention on the proportion of practical courses offered, and 
strengthening training of practical ability. Some schools also require students to obtain professional skills certificates related to their majors, thus to gain more weight for smooth employment. Therefore, whether students have a professional qualification certificate; whether they have award certificates of professional skill competition; the number of professional training hours (the proportion of total teaching hours); and the quality of professional training are indicators to be considered.

\subsection{Multiple Intelligence Advantage}

Compared with the students of public universities, the most prominent characteristics of the private universities' students are poorer cultural quality, weaker basic knowledge, and particularly unsuitable for rote-learning exam-oriented education. But according to the theory of multiple intelligences, almost everyone is smart, but the scope and nature of intelligence are different. "Everyone has his strong and weak points", the difference between students should not be a burden on education. On the contrary, facing up to the difference can turn it into a valuable resource. Students in private colleges and universities may be weak in rote memorization and logical-mathematical intelligence, but may have advantages in other aspects, such as EQ, and interpersonal intelligence. These advantages can also be beneficial to the realization of high-quality employment. Multiple-Intelligence (MI) can exert its advantages from organizational capability, coordination capability, communication skills, team work capability and execution capability.

\subsection{Low Expectation Advantage}

As for the level of employment quality, this article mainly judges through job satisfaction, which means the subjective feelings of people, and has a great relationship with expectations. If other parameters remain unchanged, the lower people's expectations, the higher of their satisfaction, and the easier it is to achieve high-quality employment. As a "vulnerable group" in exam oriented education, the expectation of private univeristy students for employment is generally low, which is an advantage instead. This advantage can be measured in terms of four aspects: graduates' expectation of salary level, employment region (big cities, small and medium-sized cities, counties and rural areas), working environment, and expectations of working in government departments and large enterprises.

\subsection{Strong Risk Tolerance.}

From graduation to high-quality employment, except for a small number of students, most of them will not be seamless links, which will be full of risks and uncertainties. If it's a startup, the risk of failure is even greater. But if they are afraid of risks and failures, overcautious and dare not to meet challenges, they won't be able to achieve high-quality employment. Private university students have experienced many failures and setbacks especially in their school life, so their ability to withstand risks is relatively strong, such as whether they are afraid of entrepreneurial failure, whether they are worried about the failure of applying for a job, whether they have experienced multiple failures in starting a business or getting hired, etc., these may be converted into an advantage, which will have important significance to achieving high-quality employment.

\section{Summary}

The above research on high quality employment of private colleges and universities is conducive to pursuing the grand goal of completely building of a moderately prosperous society by 2020 .

To achieve this goal, firstly, we must lift the 70 million poor people in rural areas out of poverty, which is the hard nut. Beyond that, there is another task that cannot be ignored, that is, to create a large middle class. There are nearly 7 million college graduates each year in China, and whether these people can achieve high-quality employment is critical to creating a large middle class. In particular, private college students, it is of great significance if they can give full play to their own advantages and achieve high-quality employment. 
Secondly, it is benefits the healthy and sustainable development of private colleges and universities. Private colleges and universities have been an important part of China's higher education system. However, due to some reasons known to all, the overall social evaluation of private colleges and universities is not high, and many of them are still struggling to survive. If the private universities can truly tap and develop their own advantages, and improve the students' employment quality obviously, it will fundamentally improve their social status, and promote the healthy and sustainable development of private colleges and universities.

Thirdly, it helps to enhance the benefits of private college students and their families. Many families in urban and rural areas in our country are saving money for sending their children to private colleges and universities for college education, in order to get a higher quality of employment than not going to university. But this does not guarantee that a satisfactory job will be obtained naturally. If going to college does not make any differences, it means that these students and their families have not received a reasonable return on their investment in education, or suffered a huge loss. After all, discovering, tapping, and developing the employment advantage of private university students is for the benefit of the students' and their families' benefits, to make their educational input worthwhile.

The Educational Authorities should consciously guide and encourage private universities to fully exert their employment advantages throughout their management, evaluation and assessment of private colleges and universities. The management of private colleges and universities can refer to these influencing factors, reform major and curriculum settings, and optimize the allocation of education and teaching resources. Meanwhile, college students can refer to these analysis factors of employment advantage, establish identity self-confidence, diathesis self-confidence, and intelligent self-confidence, enhance strengths and avoid weaknesses, therefore to achieve high-quality employment.

\section{References}

[1]. G.M. Szirony, L.G. Kontosh. (2007). Workplace issues and placement: What is high quality employment? Work. 04.

[2]. Liu xiaoyu \& Hu jungang. (2008). Empirical Analysis of the Factors Affecting the Employment of University Graduates Based on Regression Model. Journal of Jiangxi University of Finance and Economics, 02, p.115-120.

[3]. Li wenhong. (2015). Give Full Play to the Comparative Advantage and Promote the Employment Competitiveness of Students in Private Colleges and Universities. Journal of Guangdong Peizheng College, 01, p.62-66.

[4]. Huang jingbao. (2012). The Impact of Human Capital and Social Capital on the Employment Quality of College Students. Social Science of Beijing. 03.

[5]. Wei jie, Fu chunxin. (2006). Analysis of the Main Factors Affecting the Employment of Graduates of Private Universities-Based on the Survey of Five Private Undergraduate Universities in Xi'an. Education \& Economy. 04, p.46-49.

[6]. Jiang ling. (2015). Analysis of the Employment Status and Problems of Private College Graduates-Based on the Investigation of Private Universities in Anhui Province. Journal of Jiamusi Vocational College. 12, p.199-200+202.

[7]. Tang lin, et al. (2015). Research on Influencing Factors of High Quality Employment of Students in Private Colleges and Universities. Science and Technology Innovation Herald. 34, p.218-221.

[8]. Shen yijun \& Wang fang, (2015) Non-intellectual Strategies for Promoting Employment Competitiveness of Students in Private Colleges and Universities. Jiangsu Higher Education. 01, p.108-110. 